\title{
PRINCÍPIO DE LEGALIDADE E PODER DE POLÍCIA
}

CAIO TÁCITO*

A lei, como regra de conduta entre pessoas privadas, tem raízes na ordem jurídica romana.

Contudo, no plano do direito público, a autoridade real determinava, em termos absolutos, a conduta coletiva.

A vontade real tinha força de lei, como exprimia a máxima do Digesto (quod principi placuit legis vigorem habet).

SERRIGNY, em obra clássica sobre o Direito Público e Administrativo Romano, acentua o absolutismo do governo imperial e, especialmente, que a divisão de poderes era desconhecida sob o império romano.

E, a par do dever imposto pela ordem irrestrita do rei, sobrepunha-se à vontade individual a imposição dos deveres religiosos.

A lex divina, traduzida pelos sacerdotes, completa a lex regia, como expressões do poder absoluto.

As primeiras sementes dos direitos individuais nascem, na Idade Média, nos forais ou cartas de franquia outorgados em benefício de comunidades locais e se manifestam, de forma mais definida, no pacto entre João Sem Terra e os barões revoltados, que se consubstancia na Magna Carta de 1215 e se vai consolidar na Petition of Rights de 1628, confirmada no Bill of Rights, de 1689, que afirmam o controle do Parlamento sobre a autoridade real, definindo o consentimento como fonte de eficácia da lei imperial.

Contudo, o movimento histórico de consagração dos princípios da limitação e de separação dos poderes tem como marco reconhecido a doutrina moderna dos direitos individuais e a afirmação das liberdades públicas na Declaração francesa dos Direitos do Homem e do Cidadão, de 26 de agosto de 1789, ainda que a independência das colônias inglesas na América do Norte houvesse antecipado o

* Professor Emérito da UERJ.

R. Dir. Adm.,

Rio de Janeiro, 227: 39-45,

jan./mar. 2002 
reconhecimento de direitos na Declaração de Virgínia, de 12 de junho de 1976, que, com a ratificação de outros Estados, alcançaria forma permanente na Constituição promulgada em 17 de setembro de 1787.

A Revolução Francesa, no término do século XVIII, assinala a implantação do liberalismo, que se vai irradiar como modelo da sociedade do milênio seguinte, afirmando a internacionalização dos direitos fundamentais e do princípio de legalidade como fundamento de garantia da liberdade e do patrimônio, protegendo o indivíduo contra o absolutismo dos atos de Governo.

A Declaração de 1789 afirma, como finalidade, a conservação dos direitos naturais do homem, que são a liberdade, a propriedade, a segurança e a resistência à opressão $\left(\operatorname{art.} 2^{\circ}\right)$.

A liberdade consiste em poder fazer tudo que não prejudique o próximo (art. $\left.4^{\circ}\right)$, e a lei, expressão da vontade geral, deve ser a mesma para todos, seja para proteger, seja para punir (art. $6^{\circ}$ ).

As Constituições brasileiras, desde sua origem na Carta Imperial de 1824, colocam, entre seus pressupostos essenciais, a noção de que a lei é a medida necessária de deveres, direitos e obrigações, tanto nas relações privadas como no plano de atuação pública.

A Administração Pública, dotada de uma margem reconhecida de discricionariedade, em benefício do interesse geral, encontra na regra de competência, explicitada na lei que qualifica o exercício da autoridade, a extensão do poder de agir. Dissemos, em outra oportunidade, que não é competente quem quer, mas quem pode, segundo a norma de direito.

Ao contrário da pessoa de direito privado, que, como regra, tem a liberdade de fazer aquilo que a lei não proíbe, o administrador público somente pode fazer aquilo que a lei autoriza expressa ou implicitamente.

No entanto, quando as Constituições e, por via de consequiência, as leis, adotam como finalidade essencial, pôr termo ao absolutismo dos poderes do Estado, logo se tornou evidente a incompatibilidade de um novo absolutismo: o do irrestrito exercício dos direitos e liberdades individuais.

Se o direito individual tem como limite natural o direito de outrem, cumpre ao Estado o dever de garantir o equilíbrio da ordem coletiva contra os excessos do individualismo.

Nasce, por esta forma, o poder de polícia, que exprime, em sua origem clássica, o implemento de dever geral de não perturbar que se superpõe como limite à liberdade individual.

Em seu conceito clássico o poder de polícia é simples processo de contenção de excessos do individualismo. Consiste, em suma, na ação da autoridade pública para fazer cumprir por todos os indivíduos o dever de não perturbar. Um dos mestres do direito administrativo alemão assim definia o papel da administração: " $O$ resultado de cada aplicação do poder de polícia não será mais outro: que este homem não perturbe". ${ }^{1}$ 
O regime de polícia que, em sentido restrito, apenas compreende os três interesses primários da ordem, segurança e salubridade, se vai estendendo para alcançar outras formas de conciliação de interesses individuais.

Entre nós, Rui Barbosa, nos idos de 1915, já diagnosticava a dilatação do território afeto ao poder de polícia:

"Praticamente, os interesses, em que consiste o bem público, bem geral, ou bem comum, public welfare, cometido à discrição do poder de polícia, abrangem duas grandes classes: os interesses econômicos, menos diretos, menos urgentes, menos imperiosos, mais complexos, e os interesses concernentes à segurança, aos bons costumes, à ordem, interesses mais simples, mais elementares, mais preciosos, mais instantes em qualquer grau de desenvolvimento social nas coletividades organizadas e policiadas" 2 .

A passagem do tempo somente terá modificado a proporcionalidade entre os dois grupos de interesses, nivelando as duas categorias amparadas pelo poder de polícia, na medida em que o fenômeno econômico assumiu o centro do palco, mesmo em relação ao homem comum.

A ordem econômica passou a um crescente relevo na sociedade moderna, convertendo o Estado em agente de intervenção, com o objetivo de promover o bem-estar social.

Nos EUA, desde meados do século passado, a velocidade do crescimento da economia tornou necessária a presença do Estado na disciplina de direitos individuais.

A expressão police power ingressa, pela primeira vez, na terminologia legal, no julgamento pela Corte Suprema do caso Brown versus Maryland e reaparece em outros julgados, a partir de 1827 , como limite ao direito de propriedade para subordiná-lo a interesses respeitáveis da comunidade.

Tendo como origem os poderes residuais dos Estados-membros, o police power passou a exprimir a competência legislativa estadual para regular direitos privados em benefício do interesse coletivo. Como afirmado no caso Noble versus Haskell, "it may be said in a general way that the police power extends to all the great public needs". ${ }^{3}$

Em sua expressão mais ampla - apontou Mathews - a noção conduziria ao abandono da filosofia individualista do laissez faire e à aproximação do coletivismo ${ }^{4}$.

A Revolução Industrial, símbolo maior da expressão do capitalismo, faz, no entanto, retroceder, no término do século passado e no primeiro quartel do atual, o alcance do police power como fonte de ação do controle da economia e favorece a doutrina dos vested rights, segundo a qual certos direitos fundamentais estariam imunes à disciplina do governo.

2 Barbosa, Rui. Comentários à Constituição brasileira, v. 5, p. 319.

3 Willoughby. Principles of constitutional law of the United States. 2. Ed. p. 763.

4 Matheus. The American constitutional system. 1940. p. 456. 
A cláusula do due processe of law, constante da $14^{\mathrm{a}}$ Emenda, supera o seu endereço original, meramente adjetivo, para alcançar o abono da jurisprudência no sentido de firmar neutralidade do Estado em face do capitalismo dominante.

O Judiciário, de inspiração conservadora, assume supremacia política, implantando o chamado "governo dos juízes" que, nos anos da década de 1890, firma "a aliança do juiz e do capitalista, sob os auspícios dos grandes advogados da época. A Corte Suprema se torna a guardiã da ortodoxia econômica", segundo o depoimento de Roger Pinto. 5

Na medida, porém, em que os sindicatos se fortalecem e despontam os primeiros sinais da crise afinal deflagrada em 1929, retorna a primazia do poder de polícia como instrumento de intervenção do Estado na ordem econômica e social. Um novo federal police power abre caminho ao plano do New Deal e mobiliza a atividade administrativa para a regulamentação dos negócios privados.

No equilíbrio entre princípios - de certa forma antagônicos - da liberdade e da autoridade, o poder de polícia se coloca como uma das faculdades discricionárias do poder público, visando à proteção da ordem, da paz e do bem-estar social.

A crise do Estado se colocou, porém, na dimensão da passagem de um sistema de liberdade econômica, sujeita às leis do mercado, para um regime de dirigismo sob o controle do poder regulamentar (nule marking power) e do poder de planejar e socializar a economia (directing power).

Tivemos oportunidade de acentuar, em outro ensaio, as etapas sucessivas que, no plano constitucional, partiram da consagração dos direitos civis e políticos para acrescer os direitos sociais do homem e afinal acolher os direitos coletivos sem dono certo, os chamados direitos difusos. Em suma, a extensa avenida que vai do cidadão ao consumidor. Em cada uma dessas fases, em que se aperfeiçoa a busca da fidelidade ao princípio democrático, o poder de polícia é um meio indispensável de ação do governantes na prática do dever de boa administração.

O fortalecimento do poder discricionário - do qual o poder de polícia é uma das manifestações mais atuantes - colocou em destaque a necessidade de aperfeiçoamento do controle de legalidade de modo a conter, oportunamente, os excessos ou violências da administração pública.

Certamente, a via tradicional de garantia, no sistema de freios e contrapesos, incumbe, por excelência, ao poder judiciário, guardião da legalidade e protetor dos direitos e liberdades. Na medida em que se amplia, como assinalado, o poder maior do Estado, constroem-se meios mais eficazes para a prática do controle judicial. De um lado, pelo exame da constitucionalidade das leis, limita-se a ação do poder legislativo na política de intervenção notadamente na ordem econômica e social. De outra parte, aprofundou-se o controle de legalidade dos atos administrativos mediante a construção, a princípio doutrinária e jurisprudencial, da teoria do desvio de poder, notável criação do Conselho de Estado da França (que logo se internacionalizou), a qual permite condicionar a competência da autoridade, impedindo que possa ser

5 Pinto, Roger. La crise aux Etats-Unis. 1951, p. 121. 
posta a serviço de interesse que não se compatibilizem com a finalidade específica que, em cada caso, autoriza a ação unilateral e imperativa da administração pública.

Remédios especiais contra os abusos de poder administrativo se consolidaram através dos tempos. O histórico instrumento do habeas-corpus, como os modernos procedimentos do mandado de segurança (ou do amparo, que é o seu irmão gêmeo no direito mexicano e argentino), contrastam, com eficiência e celebridade, as violações ou ameaças aos direitos individuais.

Mais recente, a ação popular, prevista na Constituição, faculta a qualquer cidadão assumir o papel de defensor do interesse coletivo, quando os atos ilícitos do Estado causem dano à coisa pública.

Incorpora-se ao elenco de tais medidas de proteção ao interesse geral a adoção do processo da ação de responsabilidade do Estado para a proteção de interesses coletivos, atribuindo-se legitimação processual a associações representativas de segmentos da Sociedade (Lei n. 7.347, de 24 de julho de 1985).

Também ao poder legislativo incumbe exercer, embora indiretamente, a vigilância sobre a administração pública, de modo a coibir as ilegalidades e abusos do poder administrativo. Se não cabe ao órgão legislativo anular atos administrativos ilegais (função privativa do Judiciário) há remédios indiretos contra os abusos de autoridade, mediante pedidos de informações de iniciativa de seus membros ou, de modo mais eficaz, por meio de comissões parlamentares de inquérito (Lei n. 1.579, de 18 de março de 1952).

No cenário dos direitos humanos desponta a reação contra o risco da presença esmagadora do Estado. A título de servir ao homem e à coletividade, o Estado ameaça tornar-se opressivo, substituindo a personalidade pela uniformidade. No painel da liberdade, acendem-se as luzes de advertência do perigo do autoritarismo. Ao abuso do direito individual ou aos malefícios da concentração econômica, que a lei habilita o Estado a prevenir ou reprimir, sucede-se o abuso da burocracia, perante a qual podem ficar desarmados tanto as pessoas como os próprios setores da sociedade.

A era dos direitos sociais, na qual o Estado passa a responder pela segurança de uma parcela da sociedade contra os infortúnios da vida, faz proliferar os órgãos do serviço público.

No entanto, a consciência, que se generaliza, de que a expansão do poder do Estado constrange a liberdade e padroniza a sociedade, não se limita à criatividade de meios de defesa da privacidade do indivíduo e do espírito de iniciativa, aquilo a que chamamos a polícia do poder.

Assistimos a um progressivo retorno aos fundamentos do liberalismo, sem prejuízo das conquistas da justiça social. Há um sensível espírito de desmassificação da sociedade, uma revolta contra as hierarquias e as burocracias dominantes.

A par da ressurreição do liberalismo, como sentido de existência do homem e de reconquista da felicidade, começa também a se difundir o sentimento de participação, que se torna a bandeira da reforma social.

O caminho ficou aberto para uma nova solução liberal. O novo liberalismo soma os valores tradicionais da igualdade e da liberdade com o dever da solidariedade. Restaura o valor do indivíduo como finalidade, mas dele cobra os deveres de uma vida solidária e participativa. 
Não basta, porém, consignar, como limite ao absolutismo de direitos individuais, a faculdade atribuída à Administração Pública de conter, pela prática do poder de polícia, a eventualidade de excessos do liberalismo.

É mister que um novo absolutismo não se inaugure, contendo-se os excessos da autoridade. Ao poder de polícia deverá se opor a polícia do poder.

Neste sentido, a doutrina e a jurisprudência - e, a seguir, a própria lei conceituam como desdobramento necessário do princípio de legalidade, que a ação administrativa discricionária deve pautar-se pelo requisito essencial da finalidade como condicionante da competência da autoridade pública.

Enquanto no ato jurídico privado as razões que inspiram o autor, como o endereço de sua vontade, são em princípio de sua livre escolha, o ato jurídico público, e especialmente o ato administrativo, está vinculado a um fim público específico, ainda que a norma de competência a ele não se refira explicitamente.

Se a autoridade se desvia da finalidade legal própria, o ato administrativo se torna viciado em elemento essencial de legalidade.

Caracteriza-se, na hipótese, o vício que se conceituou como desvio de finalidade ou desvio de poder. A terminologia descreve, graficamente, o movimento ilícito da vontade que, descumprindo o comando imperativo da lei, se dirige a um alvo diverso daquele que lhe é destinado.

A noção do détoumement de pouvoir, construída na jurisprudência do Conselho de Estado da França, como vício essencial da legalidade do ato administrativo, é, por definição, um limite à ação discricionária, um freio ao transbordamento da competência legal, de modo a impedir que a ação unilateral e compulsória da autoridade possa dedicar-se à consecução de um fim de interesse privado, ou mesmo de outro fim público estranho à previsão legal.

Acolhida, amplamente, na generalidade dos sistemas administrativos, a noção de desvio de poder como tipo de ilicitude administrativa, alcançou, entre nós, consagração legislativa e jurisprudencial.

Sustentamos em estudo especial sobre o tema, que a teoria do desvio de poder como vício de legalidade vai além do controle dos atos e contratos administrativos.

Tanto o desvio de poder legislativo, como o desvio de poder jurisdicional se podem caracterizar na medida em que o legislador ou o juiz destoem, de forma manifesta, do âmbito de seus poderes, que, embora de reconhecida amplitude, não são ilimitados e atendem a fins que lhe são próprios e definidos (RDA 188/1).

O diagnóstico de compatibilidade da substância dos atos administrativos com a finalidade legal a que estão adstritos conduz a que o exame de sua validade não se contenha nos aspectos exteriores da manifestação de vontade.

$\mathrm{O}$ controle de legalidade evoluiu para verificar a existência real dos motivos determinantes da decisão administrativa, a importar no acesso à motivação expressa ou implícita do ato administrativo.

A motivação é, em certos atos, exigência legal de sua validade. Mesmo, porém, quando não exigida, cabe ao intérprete, atendo aos antecedentes que condicionam a emissão do ato de vontade do administrador, verificar se os motivos são verdadeiros e aptos a produzir o resultado. 
E, mais ainda, o exame da motivação do ato, permitirá ao controle de legalidade avaliar se o nexo causal entre os motivos e o resultado do ato administrativo atende a dois outros requisitos essenciais: o da proporcionalidade e o da razoabilidade, que são igualmente princípios fundamentais condicionantes do poder administrativo.

$\mathrm{O}$ conceito de legalidade pressupõe, como limite à discricionariedade, que os motivos determinantes sejam razoáveis e o objeto do ato proporcional à finalidade declarada ou implícita na regra de competência.

Os princípios de que a ação administrativa deve conduzir a um resultado razoável e proporcional à finalidade da lei inibe o abuso de poder $\mathrm{e} o$ arbítrio da autoridade, permitindo ao administrado a lícita fruição de seus direitos e interesses legítimos.

A atividade da Administração Pública tem como destinatários naturais as pessoas físicas e jurídicas que se subordinam à sua disciplina.

Parecerá, assim, um paradoxo que, embora deve incidir sobre pessoas, a gestão administrativa, terá de ser impessoal, mormente quando a própria Constituição impõe ao Poder Público tratamento peculiar aos integrantes de categorias distintas da coletividade, como a criança, o adolescente, o idoso ou o deficiente.

É que, segundo o aforismo grego que Rui Barbosa popularizou, a igualdade consiste em tratar desigualmente os desiguais.

Contudo, a Administração Pública tem como norma básica a proteção de interesses coletivos, ainda que peculiares a grupos definidos em lei e, por esta forma, submetidos a tratamento especial.

O princípio da impessoalidade repele atos discriminatórios que importam favorecimento ou desapreço a membros da sociedade em detrimento da finalidade objetiva de norma de direito a ser aplicada.

Não é indiferente, porém, à Administração Pública a personalidade do administrado. O que se veda é a personificação de seus atos, na medida em que abandonem o interesse público para conceder favores ou lesar pessoas ou instituições.

Em síntese, a atividade administrativa pode, e em certos casos deve, distinguir entre pessoas, em função de peculiaridades que a lei manda observar. Não poderá jamais discriminar entre elas, sobrepondo o juízo personalista à objetividade legal de tratamento.

O princípio da impessoalidade se aproxima, em suma, do princípio da imparcialidade, um e outro subordinados à regra da neutralidade e isenção administrativas.

Como assinala Maria Sylvia Zanella DI PIETRO, "a Administração não pode atuar com vistas a prejudicar ou beneficiar pessoas determinadas, uma vez que é sempre o interesse público que tem que nortear o seu comportamento."

Em suma, o princípio da legalidade, em seus sucessivos desdobramentos, confere autenticidade ao lema da Revolução Francesa, que se traduz na tríplice afirmação dos princípios da liberdade, igualdade e fraternidade.

A eles correspondem, como excelentemente documenta Manoel Gonçalves FERREIRA FILHO (Direitos Humanos Fundamentais - 1995), as três gerações de direitos fundamentais que se sucedem no tempo: os direitos individuais, os direitos sociais e os direitos difusos e coletivos, que marcam as etapas de evolução do constitucionalismo. 


\title{
Dicionário de Tecnologia Jurídica
}

\author{
Pedro Nunes
}

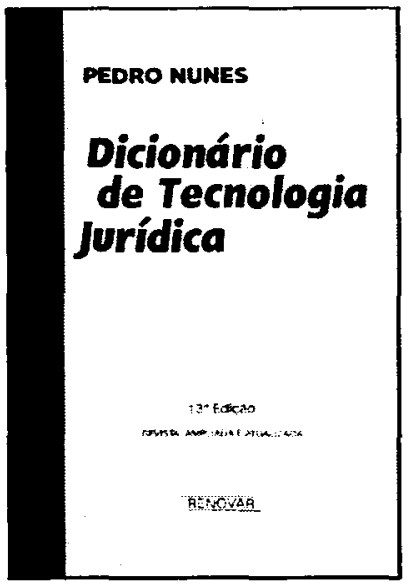

Esta obra representa um caminho de pesquisa seguro, para o estudante. O Atualizador não olvidou o material existente, antes procurou seguir o mesmo modo didático de se tratar cada verbete. Com efeito, mesmo ampliada, esta nova edição segue o mesmo padrão de tratamento para cada instituto jurídico. Este é um livro que, muito embora seja direcionado para um público, é também encaminhado a todos aqueles que, eventualmente, se deparam com termos jurídicos não conhecidos.

Ref. 0223

Form. 16x23

Encadernado

1.198 págs. 1999 $13^{a}$ edição

\section{Direito Agrário}

Rafael Augusto de Mendonça Lima

O autor enfatiza aqui o Estatuto da Terra e leis complementares e exalta a importância do Direito Agrário no âmbito legislativo, na doutrina e no ensino jurídico. O Direito Agrário tem princípios e institutos próprios, que servem como critérios para a elaboração das leis agrárias e para a sua interpretaçāo. Essa é a matéria tratada neste livro, atualizada de acordo com a Constituiçāo Federal de 1988, a legislação ordinária e a doutrina.

Ref. 0076

Form. 14x21
Brochura 1997
512 págs. $2^{\text {a }}$ ed.
RNAEL AUGUSTO DE ME NDOMUCA LIMA

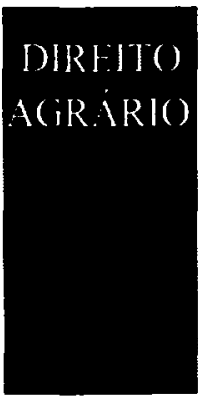

24 EOtÇAo

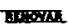

